Vol. 39(1), pp. 28-38, June 2021

ISSN 1821-536X (print)

ISSN 2619-8789 (electronic)
Tanzania Journal of Engineering and Technology

Copyright $\odot 2021$ College of Engineering and

Technology, University of Dar es Salaam

Full Length Research Paper

\title{
Prediction of four-days Soaked California Bearing Ratio (CBR) Values from Soil Index Properties
}

\author{
Pascal Ambrose ${ }^{1}$ and Siya Rimoy ${ }^{2}$ \\ ${ }^{1}$ Tanzania National Roads Agency (TANROADS), Ministry of Works and Transport, Dodoma, \\ Tanzania. E-mail: ambrosep02@gmail.com \\ ${ }^{2}$ Department of Transportation and Geotechnical Engineering, University of Dar es Salaam, Dar es \\ Salaam, Tanzania. E-mail: rimoy@udsm.ac.tz
}

\begin{abstract}
California Bearing Ratio (CBR) laboratory testing is the conventional method for determining soaked strengths of pavement subgrades. The test requires careful preparation of soil samples followed by four days of water soaking before penetrating the samples using a standard plunger at prescribed rates to set depths. When the number of samples becomes large the determination of soaked CBR values becomes cumbersome as the test is laborious and time consuming. This study aimed at establishing an alternative way of determining soaked CBR by developing a model that would be used for estimating soaked CBR of fine- and coarse-grained soils without performing the CBR test. This has been achieved by correlating CBR values compacted at 95\% Maximum Dry Density (MDD) with the soil index properties. The results show that soaked CBR values of fine-grained soils significantly correlate with specific gravity of soil (GS), Plasticity index (PI) and the grading modulus $(G M)$ of the soil that yields a degree of determination of $R^{2}=0.91$ and for coarse grained (A-2 type) soil, the soaked CBR values significantly correlate with specific gravity of soil and percentage of fines passing $0.075 \mathrm{~mm}$ sieve size that yields a degree of determination of $R^{2}=0.94$.
\end{abstract}

Keywords: Four-days soaked California Bearing Ratio (CBR), Soil Index Properties, Subgrade.

\section{INTRODUCTION}

The California Bearing Ratio (CBR) test is the most widely used test method to evaluate and classify the potential strength of compacted soil subgrade, subbase, base coarse or recycled materials for use in road and airfield pavement design and construction. Given the inherent variability of soils as a natural material, different soils will have different CBR values even if they are compacted at the same amount of energy (Carter and Bentley, 1991). Typical pavement design practices require input of representative CBR values from laboratory tests on four-days soaked compacted near to Maximum Dry Density (MDD) samples taken along proposed alignments in accordance to AASHTO (T193). This requires relatively substantial quantities of soil samples, it is time consuming, and costly. In such, subgrade CBR testing frequencies are practically limited to two (2) points per $\mathrm{km}$ assuming homogeneity or uniform transitions for intermediate sections. The main objective of this study 
was to develop a four-days soaked CBR predictive model based on soil index properties that best suit the types of soils in Tanzania so as to improve the predictive reliability of CBR along road alignments quickly and cost optimally. This has been achieved by establishing correlation between Laboratory soaked CBR values compacted at $95 \%$ MDD and soil characteristics that suit the type of soils along the study area. Black (1961) reported that for both sands and clays laboratory and in-situ CBR values can be calculated from measurements of cohesion, angle of shearing resistance, and suction by invoking the shallow ultimate bearing capacity general shear failure equation in accordance with Terzaghi (1943). Black (1961) recognised and offered corrections for the constraining scale effect of the $152 \mathrm{~mm}$ diameter mould on the deformation of the $50 \mathrm{~mm}$ plunger, a mould to plunger diameter ratio of 3.0. More recently substantial scale effects have been reported in physical modelling at even much large diameter ratios (Rimoy et al., 2015; de Graft-Johnson and Bhatia, 1969; Agarwal and Ghanekar, 1970), The Mechanistic Empirical Pavement Design Guide by the National Cooperative Highway Research Program (NCHRP), Patel and Desai (2010), Venkatasubramanian and Dhinakaran (2011), Sathawara and Patel (2013), Rakaraddi and Vijay (2015) and others developed empirical equations or models for CBR values predictions from basic soil properties. The need for the current study raised from the fact that published equations gave very poor predictive reliability when used on a collated database of unbound granular materials from Tanzania deposits.

\section{MATERIALS AND METHODS}

To achieve the objective of the study, fourdays soaked CBR laboratory test data for pavement design from three road projects in Lindi and Mtwara regions in Tanzania were used;

i. Upgrading of Tunduru - Mangaka

- Mtambaswala road to bitumen standard LOT 1 Mangaka Nakapanya $(70.5 \mathrm{~km})$ project;

ii. Upgrading of Nanganga Ruangwa $(60 \mathrm{~km})$ and Ruangwa Matambale (Nachu mine access) Road project; and

iii. Upgrading of Masasi Nachingwea - Nanganga road $(112 \mathrm{~km})$.

The three projects are all trunk roads under the management of Tanzania National Roads Agency (TANROADS) on behalf of the Government of the United Republic of Tanzania. The chosen sections sit on a major superficial geological formation in Tanzania consisting of Achaean marble quartzite's, graphitic schist, chlorite, amphibole, mica and kyanite schist, hornblende, biotite and garnet gneiss, acid gneiss, granulites and charnockite (Figure $1)$.

Samples for laboratory testing were retrieved from the study sites by manual bulk disturbed sampling from the trial pits listed in Ambrose (2018) using techniques and procedures specified in PMDM (1999). Laboratory soil test data selected from the study area consisted of CBR, Optimum Moisture Content (OMC), Maximum Dry Density (MDD), Particle Size Distribution (PSD), specific gravity of soil (GS), Plasticity Index (PI) and Grading Modulus (GM) determined in accordance to methods described in CML (2000). Graphical correlation methods as well as statistical functions integrated in Microsoft Excel by the use of regression model tool were used for the analysis of data. Twenty five (25) fine-grained test points in the dataset were selected for model development and the following information was captured; identification of the trial pit tested, chainage location of the trial pit along the selected case study 
alignment, the four-days soaked CBR value, the maximum dry density, the optimum moisture content, the specific gravity, the plasticity index and the grading modulus. For each of the 26 course-grained test points similar information was captured except for plasticity index which was substituted by the percentage of fines in the soils.

The mechanism of the CBR tests is considered as a shallow bearing capacity failure (Terzaghi 1943) of the remoulded compacted laboratory specimens. With the restrictive ratio of mould diameter (152 $\mathrm{mm})$ to CBR plunger diameter $(50 \mathrm{~mm})$ giving $\mathrm{d}_{\text {chamber }} / \mathrm{d}_{\text {plunger }}=3.0$, relatively higher resistance to typical bearing capacity is expected from the rigid boundary effects. The displacement of the plunger on testing was $2.5 \mathrm{~mm}(5 \%$ $\left.\mathrm{d}_{\text {plunger }}\right)$ to $5.0 \mathrm{~mm}\left(10 \% \mathrm{~d}_{\text {plunger }}\right)$ at a rate of
$1.25 \mathrm{~mm} / \mathrm{min}$, which is sufficient to develop general shallow bearing capacity failure. Given this, it is discernible that CBR will be a function the soils' shearing resistance characteristic and density state. For the case of coarse grained cohesionless soils the shearing resistance is represented by the angle shearing resistance $\Phi^{\prime}$ either peak or constant volume/ zero dilation while for fine grained cohesive soils the undrained shear strength, $s_{u}\left(c_{u}\right)$. The density state of CBR test samples is typically set proportionate to the soils MDD. Best fit correlations of index properties to shearing resistance properties have been proposed with some being known to have improved predictive reliability than others which provides a first level indication of the potentiality of modelling CBR from index properties direct.

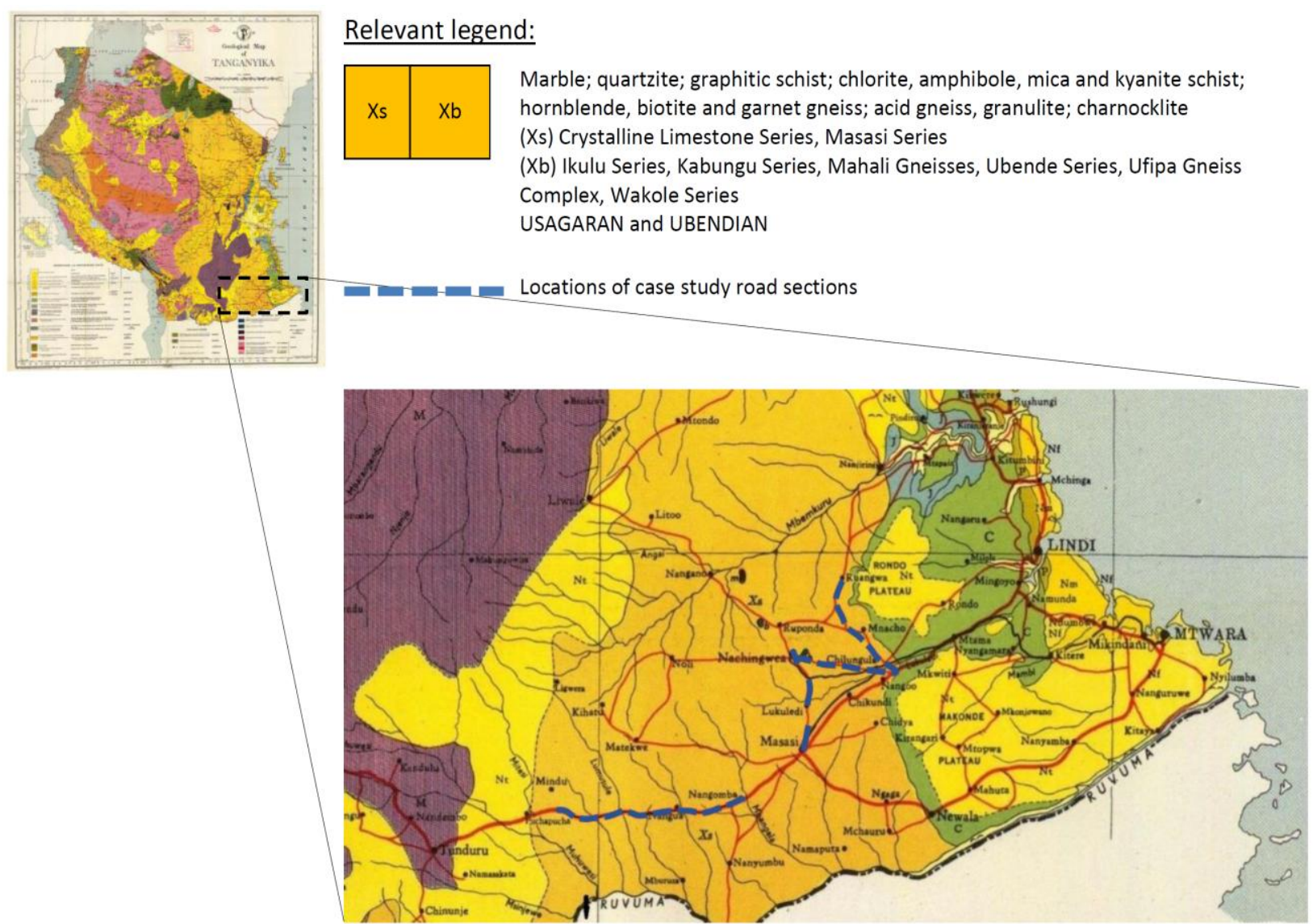

Figure 1: A not-to-scale extract from the Geological Map of Tanzania showing the geology and locations of the road sections used in this study (GST, 1959). 


\section{RESULTS AND DISCUSSION}

\section{Development of CBR Model for Fine-Grained}

Soil

The four-days soaked CBR values models were developed by the use of various soil index properties whereby laboratory fourdays soaked CBR being the response variables while the explanatory variables were the soil index properties, which were specific gravity (GS), plasticity index (PI) and grading modulus (GM) of the soil. With $95 \%$ confidence interval the outcome of the regression analysis is shown in Tables 1 and 2 . The coefficient of determination $\left(\mathrm{R}^{2}\right)$ of 0.91 was reported for the fine-grained soils, which confirms that the model is strong. Table 1 presents the overall validity of the model via Analysis of Variance (ANOVA) and as it can be seen significance $F$ ( $p$-value) is 3.29 $\mathrm{x} 10^{-11}$, which is much smaller than $5 \%$ significance value set in the model. From Table 2 the fitted model is shown by equation (1).

\section{$4-$ days soaked $\mathrm{CBR}_{\text {fine }}^{95 \%}=10(\mathrm{GS})-0.3(\mathrm{PI})+4(\mathrm{GM})-20 \ldots \ldots \ldots \ldots \ldots \ldots 1$}

It can also be seen that p-value which tests each individual explanatory variables and intercepts both are much smaller than $5 \%$ significance value set in the model and confirm that the explanatory variables are significant. The last two columns provide 95\% confidence interval for intercept and other three regression slopes for specific gravity, plasticity index and grading modulus of soil materials. Figure 2 compares the laboratory observed (measured) CBR values used to develop the model to the CBR values predicted by the model showing a relatively tight fit to the equality line.

\section{Development of CBR Model for Coarse-Grained Soils}

A similar approach to the fine-grained soils model development was used in the coarse-grained soils CBR values prediction model development, in this case using two explanatory variables, specific gravity (GS) and percentage passing sieve size number 200 (75 microns). Again 95\% confidence interval was set and the outcome of the regression analysis is summarised on Tables 3 and 4. The reported $\mathrm{R}^{2}=0.94$ for coarse-grained soils confirms that the model is strong. Table 3 presents the overall validity of the model using ANOVA and shows that significance $\mathrm{F}$ (p-value) is $6.9 \times 10^{-14}$, which is much smaller than $5 \%$ significance value set implying evidence of linear relationship of the explanatory variables. From the Table 4 the fitted model is shown by equation (2).

The last two columns provide 95\% confidence interval for intercept and other three regression slopes for specific gravity of soil and percentage passing to sieve No. 200. Figure 3 compares the CBR values used to develop the model to the CBR values predicted by the model showing a relatively tight fit to the equality line.

4 -days soaked $\mathrm{CBR}_{\text {coarse }}^{95 \%}=125(\mathrm{GS})-0.4(\%$ ge passing No. 200 sieve $)-200 \ldots \ldots \ldots .2$ 
Prediction of four-days Soaked California Bearing Ratio (CBR) Values from Soil Index Properties

Table 1: F-Test ANOVA overall validity of the developed model for fine-grained soils CBR values prediction based on index properties

\begin{tabular}{|l|c|c|c|c|c|}
\cline { 2 - 6 } \multicolumn{1}{c|}{} & df & SS & MS & F & Significant F \\
\hline Regression & 3 & 201.71 & 67.236 & 71.847 & $3.29 \times 10^{-11}$ \\
\hline Residual & 21 & 19.65 & 0.9358 & & \\
\hline Total & 24 & 221.36 & & & \\
\hline
\end{tabular}

Where df is degree of freedom, MS is Mean Squares and SS is Sum of Squares.

Table 2: Coefficient values of the developed model for fine-grained soils CBR values prediction based on index properties

\begin{tabular}{|l|c|c|c|c|c|c|}
\cline { 2 - 7 } \multicolumn{1}{c|}{} & Coefficient & $\begin{array}{c}\text { Standard } \\
\text { Error }\end{array}$ & t-Stat & p-value & $\begin{array}{c}\text { Lower } \\
\mathbf{9 5 \%}\end{array}$ & $\begin{array}{c}\text { Upper } \\
\mathbf{9 5 \%}\end{array}$ \\
\hline Intercept & -20 & 7.26 & -2.85 & 0.0095 & -35.82 & -5.63 \\
\hline GS & 10 & 2.55 & 4.10 & 0.0005 & 5.15 & 15.76 \\
\hline PI & -0.3 & 0.07 & -4.33 & 0.0003 & -0.44 & -0.15 \\
\hline GM & 4.0 & 0.60 & 6.48 & $2.03 \times 10^{-06}$ & 2.62 & 5.10 \\
\hline
\end{tabular}

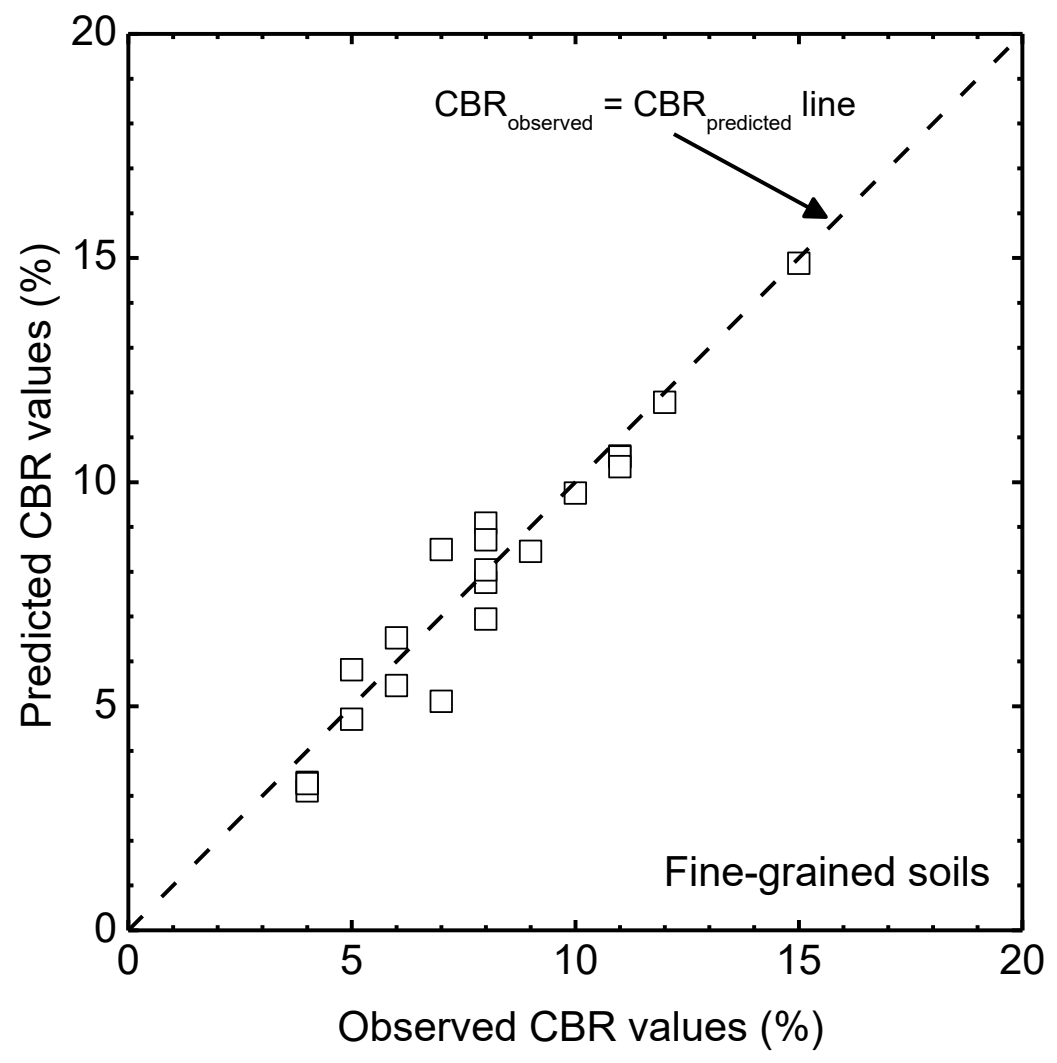

Figure 2: Comparison of CBR values used to develop the model to the CBR values predicted by the model 
Table 3: F-Test ANOVA overall validity of the developed model for coarse-grained soils CBR values prediction based on index properties

\begin{tabular}{|l|c|c|c|c|c|}
\cline { 2 - 6 } \multicolumn{1}{c|}{} & df & SS & MS & F & Significant F \\
\hline Regression & 2 & 7347.91 & 3673.95 & 161.93 & $6.9 \times 10^{-14}$ \\
\hline Residual & 22 & 499.13 & 22.69 & & \\
\hline Total & 24 & 7847.04 & & & \\
\hline
\end{tabular}

Table 4: Coefficient values of the developed model for fine-grained soils CBR values prediction based on index properties

\begin{tabular}{|l|c|c|c|c|c|c|}
\cline { 2 - 7 } \multicolumn{1}{c|}{} & Coefficient & Standard Error & t-Stat & p-value & Lower 95\% & Upper 95\% \\
\hline Intercept & -200 & 21.11 & -9.43 & $3.48 \times 10^{-09}$ & -242.89 & -155.31 \\
\hline GS & 125 & 9.10 & 13.55 & $3.73 \times 10^{-12}$ & 104.35 & 142.06 \\
\hline Sieve No. 200 & -0.4 & 0.17 & -2.31 & 0.03 & -0.73 & -0.04 \\
\hline
\end{tabular}

\section{Validation of the Developed Models}

The developed models for fine and coarsegrained soil were validated using a new set of subgrade alignment data collected from different road sections along the MasasiNachingwea-Nanganga road project and Nanganga-Ruangwa road in Lindi region. The model validation database is from a similar geological formation as the development database. Tables 5 and 6 summarises the dataset used for validation of developed models.

\section{Validation of the fine-grained soil soaked CBR prediction model}

The developed four-days soaked CBR values prediction model for fine grained soil that is presented in Equation (1) was validated by 20 numbers of laboratory soil data. The graph for laboratory observed CBR values against the values predicted by the model is presented in Figure 3 . The $\mathrm{R}^{2}=0.80$ suggests that the ability for the developed model to predict the CBR values is considered to be strong. It was observed that there are minor differences as the maximum deviation is $30.70 \%$ and, in some cases, the minimum deviation is less than $-25.5 \%$. Hence, it can be concluded that CBR of fine-grained soil bears significant correlation with specific gravity (GS) of soil, Plasticity Index (PI) of soil and grading modulus of soil (GM).

\section{Validation of Developed CBR prediction model for coarse-grained soils}

The developed four-days soaked CBR prediction model for coarse grained soils that has been presented in Equation (2) was validated by 20 laboratory soil data> The graph that shows trends of predicted against observed CBR values shown in Figure 3 indicates that predicted values are within the line of best fit that is presented by $\mathrm{R}^{2}=0.93$. Furthermore, a comparison of the laboratory observations and predicted CBR values indicates that there are minor differences as the maximum deviation is $26.8 \%$ and in some cases the minimum deviation is less than $28.8 \%$. Therefore, it can be concluded that CBR of a coarse grained soil bears significant correlation with specific gravity (GS) of soil and fineness of the materials that passing to $0.075 \mathrm{~mm}$ sieve. 


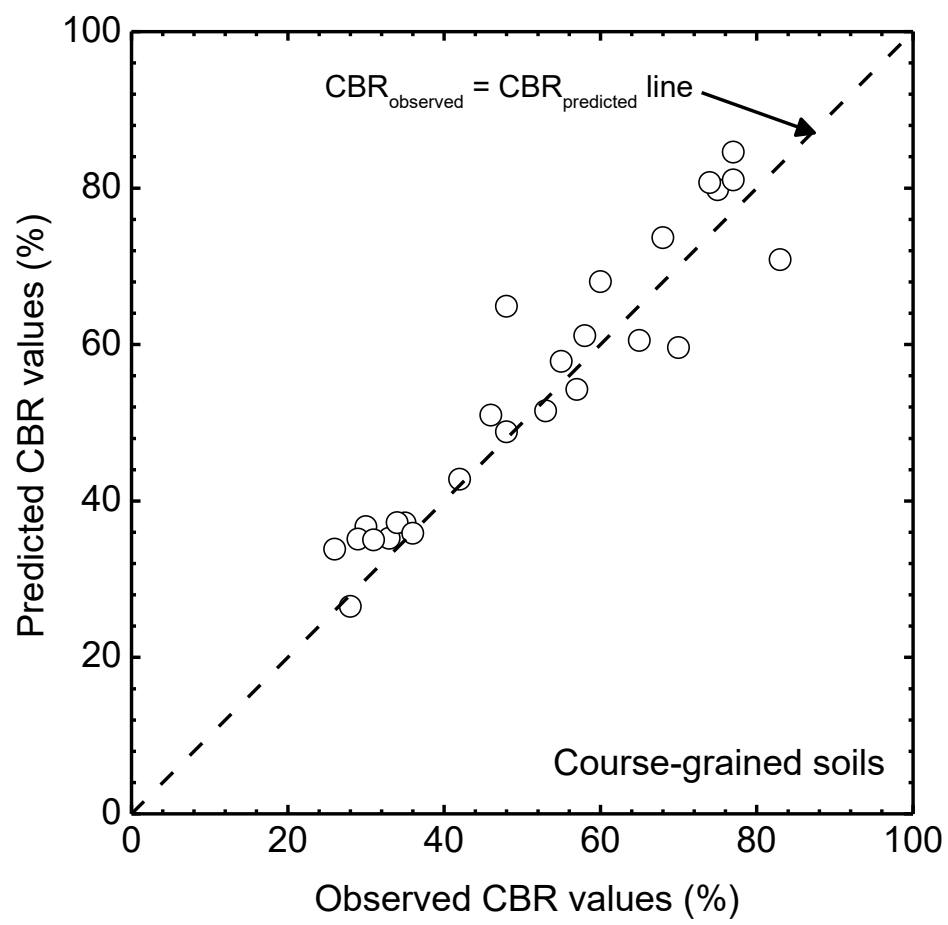

Figure 3: Comparison of CBR values used to develop the model to the CBR values predicted by the model

Table 5: Summary table of Masasi - Nachingwea - Nanganga Road section test results used for validation of fine-grained soils CBR values prediction model based on soil index properties

\begin{tabular}{|c|c|c|c|c|c|c|}
\hline S/N & CBR (\%) & MDD (kg/m3) & OMC 9\%) & GS & PI (\%) & GM \\
\hline 1. & 3 & 1848 & 10.2 & 2.61 & 18 & 0.86 \\
\hline 2. & 8 & 1923 & 13.5 & 2.73 & 16 & 1.35 \\
\hline 3. & 7 & 1936 & 16.2 & 2.80 & 16 & 1.17 \\
\hline 4. & 11 & 1989 & 14.8 & 2.86 & 14 & 1.62 \\
\hline 5. & 8 & 1876 & 11.3 & 2.73 & 14 & 1.43 \\
\hline 6. & 8 & 1988 & 13.6 & 2.73 & 12 & 1.23 \\
\hline 7. & 7 & 1890 & 11.2 & 2.79 & 12 & 1.00 \\
\hline 8. & 9 & 1960 & 11.6 & 2.81 & 14 & 1.43 \\
\hline 9. & 9 & 1988 & 14.6 & 2.80 & 15 & 1.56 \\
\hline 10. & 11 & 1982 & 14.0 & 2.86 & 15 & 1.68 \\
\hline 11. & 3 & 1882 & 11.6 & 2.61 & 18 & 0.92 \\
\hline 12. & 4 & 1828 & 16.3 & 2.62 & 19 & 0.99 \\
\hline 13. & 5 & 1928 & 10.7 & 2.66 & 21 & 1.16 \\
\hline 14. & 6 & 1958 & 11.7 & 2.75 & 17 & 0.95 \\
\hline 15. & 4 & 1966 & 15.7 & 2.62 & 16 & 0.52 \\
\hline 16. & 7 & 1998 & 13.0 & 2.74 & 17 & 1.00 \\
\hline 17. & 5 & 1799 & 10.2 & 2.65 & 18 & 0.93 \\
\hline 18. & 6 & 1958 & 11.3 & 2.86 & 15 & 1.35 \\
\hline 19. & 6 & 1822 & 14.5 & 2.75 & 16 & 0.99 \\
\hline 20. & 7 & 1898 & 18.4 & 2.81 & 16 & 1.46 \\
\hline
\end{tabular}




\section{Pascal Ambrose and Siya Rimoy}

Table 6: Summary table of Masasi - Nachingwea - Nanganga Road section test results used for validation of coarse-grained soils CBR values prediction model based on soil index properties

\begin{tabular}{|c|c|c|c|c|c|}
\hline S/N & CBR (\%) & MDD (kg/m3) & GS & OMC (\%) & \%ge fineness \\
\hline 1. & 44 & 1998 & 2.04 & 9.2 & 21 \\
\hline 2. & 45 & 2000 & 2.04 & 7.8 & 22 \\
\hline 3. & 26 & 1928 & 1.96 & 7.2 & 31 \\
\hline 4. & 80 & 2200 & 2.24 & 6.5 & 17 \\
\hline 5. & 88 & 2246 & 2.29 & 7.2 & 24 \\
\hline 6. & 59 & 2046 & 2.09 & 6.8 & 15 \\
\hline 7. & 50 & 2000 & 2.04 & 6.7 & 11 \\
\hline 8. & 42 & 1988 & 2.03 & 6.1 & 26 \\
\hline 9. & 54 & 2038 & 2.08 & 5.5 & 20 \\
\hline 10. & 82 & 2228 & 2.27 & 7.3 & 27 \\
\hline 11. & 40 & 2000 & 2.04 & 7.9 & 28 \\
\hline 12. & 44 & 1986 & 2.02 & 8.8 & 20 \\
\hline 13. & 47 & 2010 & 2.05 & 8.7 & 19 \\
\hline 14. & 55 & 2042 & 2.08 & 7.4 & 18 \\
\hline 15. & 55 & 2040 & 2.08 & 6.6 & 21 \\
\hline 16. & 35 & 1946 & 1.98 & 7.2 & 22 \\
\hline 17. & 46 & 2036 & 2.07 & 6.6 & 24 \\
\hline 18. & 50 & 2000 & 2.04 & 7.4 & 17 \\
\hline 19. & 36 & 1948 & 1.99 & 7.5 & 23 \\
\hline 20. & 63 & 2091 & 2.13 & 7.2 & 20 \\
\hline
\end{tabular}

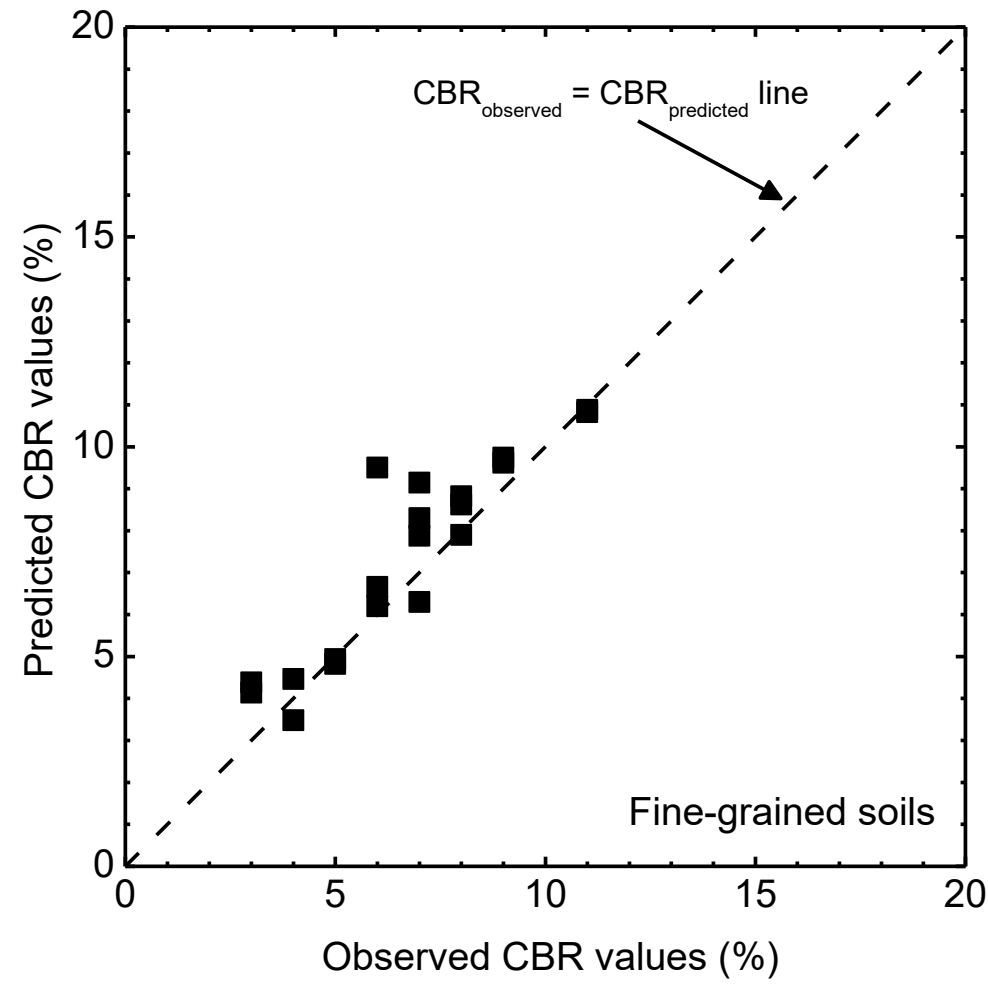

Figure 3: Comparison of laboratory observations to model predictions for validation of the four-days soaked CBR prediction model for fine-grained soils 


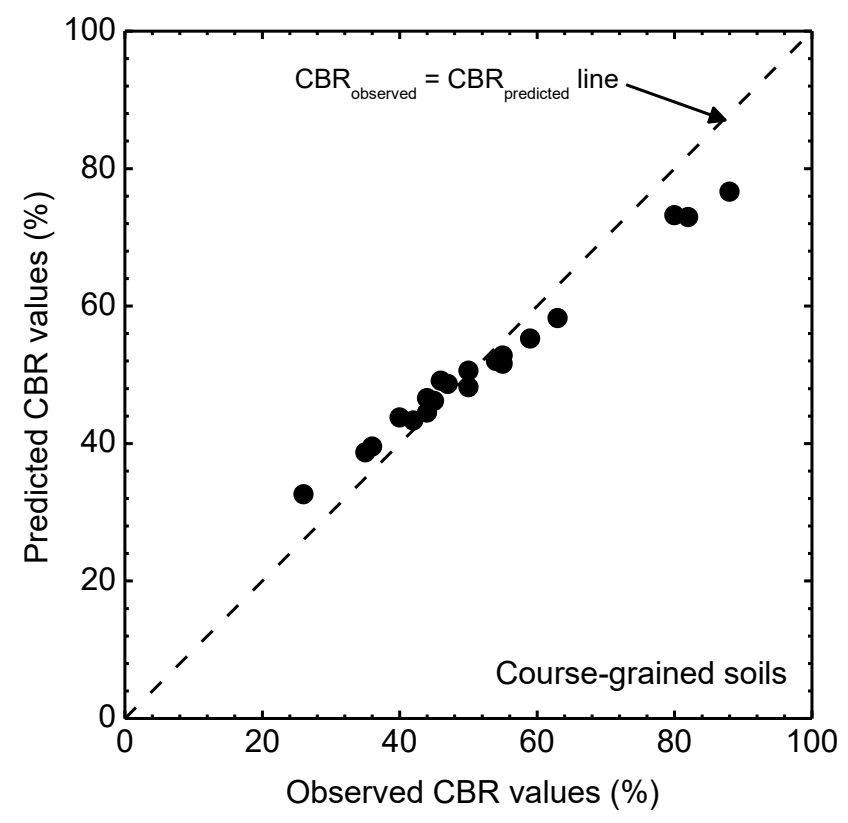

Figure 4: Comparison of laboratory observations to model predictions for validation of the four-days soaked CBR prediction model for course-grained soils

Effectiveness of the developed model compared to the selected published models

The effectiveness of the newly developed models for fine- and coarse-grained soil were compared to published existing models using a set of soil data collected from a different study area (Ambrose,
2018). The efficiency of the models was checked based on coefficients of determination $\left(\mathrm{R}^{2}\right)$, standard error of the estimates and coefficient of variations. Based on these assessments it can be concluded that, at $95 \%$ significant level, the developed model is powerful to predict soaked subgrade CBR values for such type of soil considered under the study area.

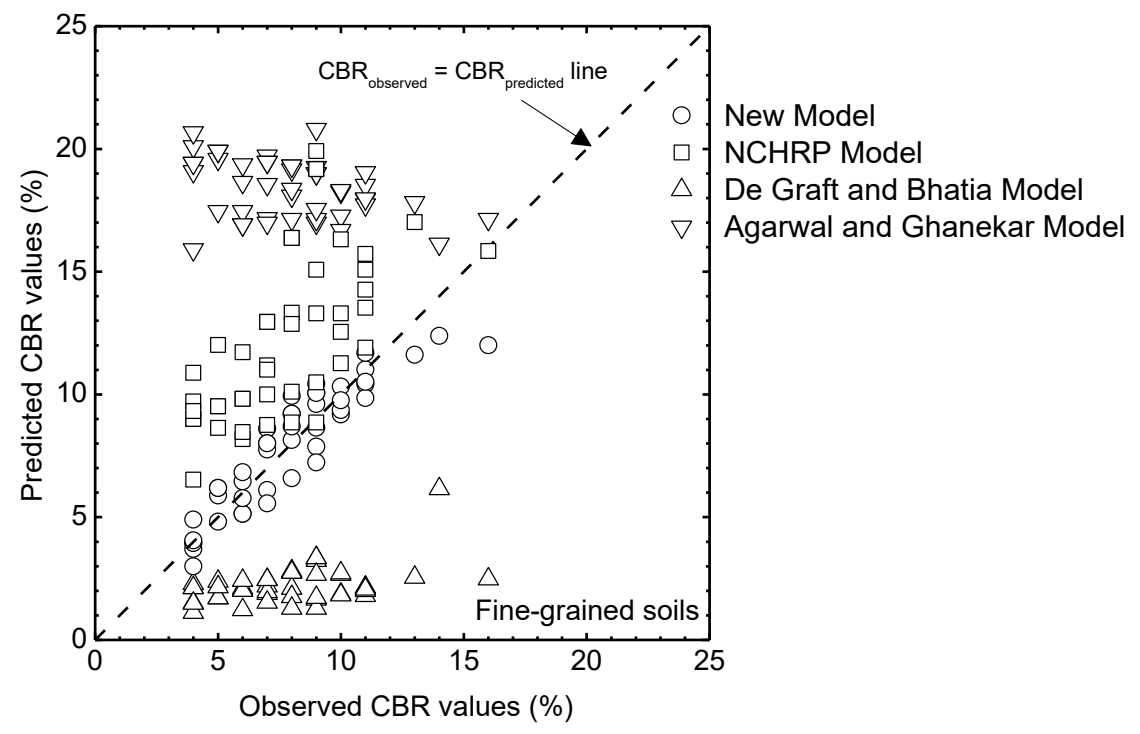

Figure 5: Comparison of effectiveness of the newly developed four-days soaked CBR values for fine-grained soils to other selected models 
Table 7: Comparison of new developed model to existing models for fine-grained soil

\begin{tabular}{|l|c|c|c|c|}
\hline Model Name & $\begin{array}{l}\text { New Developed } \\
\text { Model }\end{array}$ & $\begin{array}{l}\text { NCHRP's } \\
\text { Model }\end{array}$ & $\begin{array}{l}\text { De Graft and } \\
\text { Bhatia Model }\end{array}$ & $\begin{array}{l}\text { Agarwal and } \\
\text { Ghanekar Model }\end{array}$ \\
\hline $\mathbf{R}^{\mathbf{2}}$ & 0.79 & 0.47 & 0.30 & 0.21 \\
\hline Standard error & 1.8 & 5.9 & 65.4 & 5.6 \\
\hline Coefficient of Variation & 5.1 & 12.2 & 126.6 & 8.6 \\
\hline
\end{tabular}

Table 8: Comparison of new developed models to existing published models for coarse grained soil

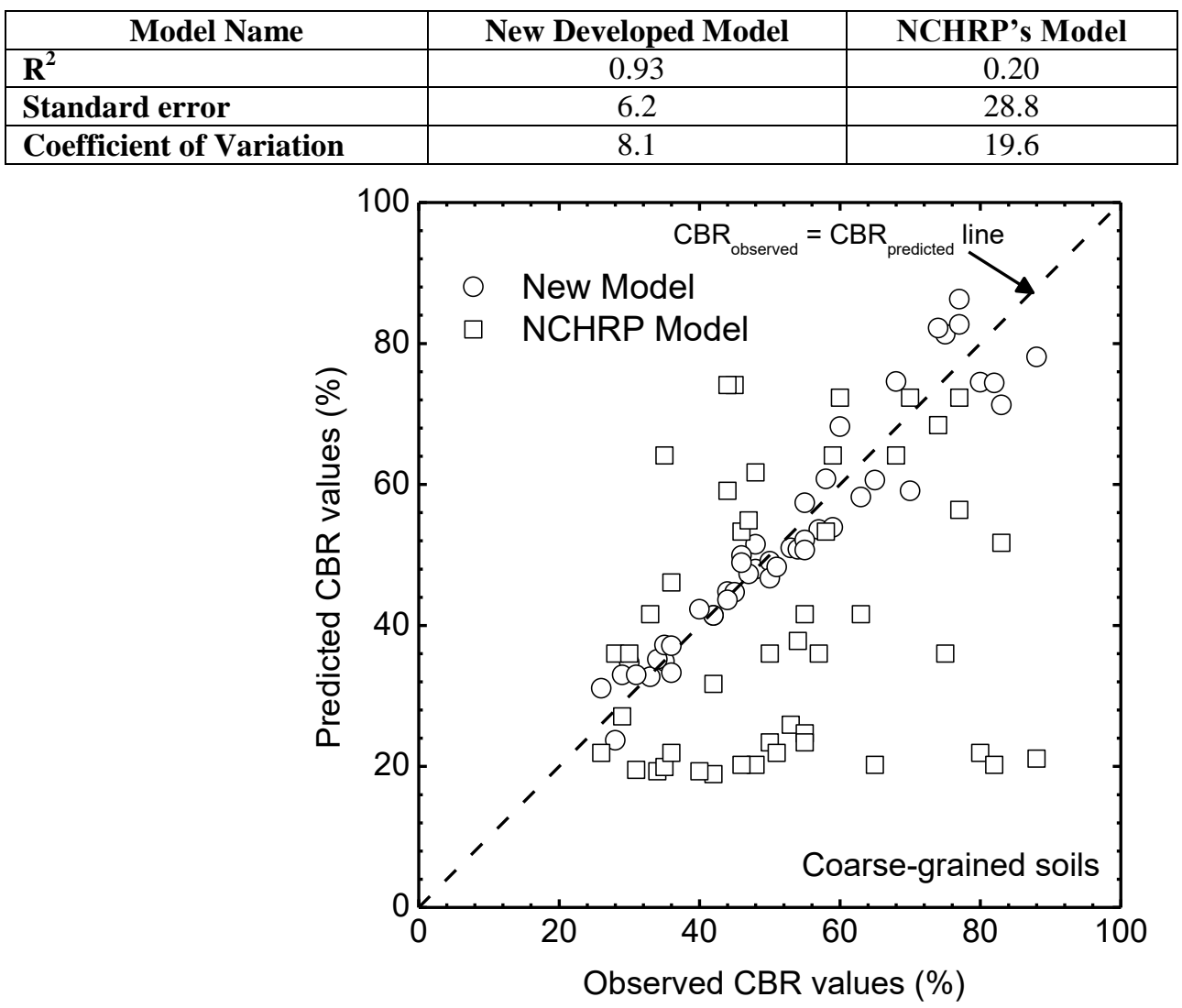

Figure 6: Comparison of effectiveness of the newly developed four-days soaked CBR values for coarse-grained soils to other selected models

\section{CONCLUSIONS}

The following conclusions can be drawn from the results of this study:

1. For fine-grained soils, the statistical parameters indicate that, the model developed by Multiple Linear Regression Analysis, which correlates four-days soaked CBR value with specific gravity of soil (GS), plasticity index of the material (PI) and grading modulus of soil (GM) yields degree of determination of $\mathrm{R}^{2}=0.91$.
2. The model developed by multiple linear regression analysis for coarse grained soils which correlates four-days soaked CBR value with specific gravity of soil (GS) and percentage of fines passing through $0.075 \mathrm{~mm}$ sieve size that yield degree of determination of $\mathrm{R}^{2}=0.94$ and shows good performance to A-2 type of soil that consists of fine materials of less than $35 \%$ passing to $0.075 \mathrm{~mm}$ BS sieve size.

3. Finally, it can be concluded that the use of index properties such as grain size analysis, specific gravity of soil, 


\section{Prediction of four-days Soaked California Bearing Ratio (CBR) Values from Soil Index Properties}

plasticity index and grading modulus of soil, gives a reasonable estimation of four-days soaked CBR value of soils.

\section{REFERENCES}

AASHTO T193-99 (2003). Standard method of Test for CBR (California Bearing Ratio) of LaboratoryCompacted Soils. American Association of State Highway and Transportation Officials, USA.

Agarwal K.B. and Ghanekar K.D. (1970). Prediction of CBR from Plasticity Characteristics of Soil. Proceeding of 2nd South-east Asian Conference on Soil Engineering, Singapore. June 1115, Asian Institute of Technology, Bangkok, Thailand, 571-576.

Ambrose P.S. (2018). Development of soaked California Bearing Ratio (CBR) Values Prediction Models Based on Soil Index Properties. MSc. (Highway Engineering) Dissertation, University of Dar es Salaam.

Black W.P.M. (1961). The Calculation of Laboratory and In-situ Values of California Bearing Ratio from Bearing Capacity Data. Geotechnique. 11(1): 14-21.

https://doi.org/10.1680/geot.1961.11.1. $\underline{14}$

Carter M. and Bentley S.P. (1991). Correlations of Soil Properties. London: Pentech Press Available online at https://trove.nla.gov.au/work/6459875. Accessed on 5th May 2021.

Central Materials Laboratory (2000). Laboratory Testing Manual. Ministry of Works and Transport, The United Republic of Tanzania.

de Graft - J.J.W.S. and Bhatia H.S. (1969). The Engineering Characteristics of the Lateritic Gravels of Ghana. Proceedings of 7th International Conference on Soil Mechanics and Foundation Engineering, Mexico. August 28-29.
Asian Institute of Technology. Bangkok, Thailand, 2: $13-43$.

Geological Map of Tanganyika (1959). Geological Survey Department Dodoma Ministry of Energy and Minerals, Tanzania.

National Cooperative Highway Research Program (2001). Guide for Mechanistic and Empirical - Design for New and Rehabilitated Pavement Structures, Final Document. In: Appendix CC-1: Correlation of CBR Values with Soil Index Properties. West University Avenue Champaign, Illinois: Ara, Inc.

Patel R.S. and Desai M.D. (2010). CBR Predicted by Index Properties of Soil for Alluvial Soils of South Gujarat. Indian Geotechnical Conference, Proc. IGC, 1: 79-82.

Pavement and Materials Design Manual (1999). Ministry of Works and Transport, Tanzania, May, 1999. ISBN $9987-8891-1-5$.

Rakaraddi P.G. and Gomarsi V. (2015). Establishing relationship between CBR with Different Soil Properties. International Journal of Research in Engineering and Technology (IJRET), 4(2): 182-188. Available online at http://www.ijret.org

Rimoy S., Silva M., Jardine R.J., Yang Z.X., Zhu B.T. and Tsuha C.T.C.H. (2015). Field and model investigations into the influence of age on axial capacity of displacement piles in silica sands. Géotechnique, 65(7): 576-589. https://doi.org/10.1680/geot.14.P.112

Sathawara J. K. and Patel A.K. (2013). Comparison between soaked and unsoaked CBR. International Journal of Advanced Engineering Research and Studies, 2(3): 132-135.

Terzaghi K. (1943). Theoretical soil mechanics. John Wiley, New York.

Venkatasubramanian C. and Dhinakaran G. (2011). ANN model for predicting CBR from index properties of soils. International Journal of Civil and Structural Engineering, 2(2): 605-611. 